\title{
QUISTE DE URACO COMPLICADO. DIAGNOSTICO DIFERENCIAL DE ABDOMEN AGUDO. REPORTE DE UN CASO
}

\author{
CYST OF URACHUS COMPLICATED. DIFFERENTIAL DIAGNOSIS OF \\ ABDOMEN ACUTE. CASE REPORT
}

\author{
Leo Tomayquispe-De-la-cruz ${ }^{1,2, a}$, Maritza Paredes-Maritza ${ }^{1,2, b}$ \\ 1. Hospital San José de Chincha, Ica, Perú. \\ 2. Universidad Nacional San Luis Gonzaga de Ica \\ a. Residente de Radiología \\ b. Medico Radiólogo
}

DOI: https://doi.org/10.35563/rmp.v9i1.298

\section{RESUMEN}

Reporte de caso: La literatura manifiesta que el quiste de uraco es raro, por lo cual el diagnóstico es aún más difícil de establecer, debido a que solo se presentan síntomas cuando ya existe una complicación, por tanto se puede suponer que algunas personas sean poseedoras de un quiste de uraco y sin presentar sintomatología, siguen con sus actividades de la vida sin problemas. A continuación, presentamos el caso de una paciente, que ingreso con una clínica sugerente de abdomen agudo por apendicitis, pero los exámenes de imágenes revelaron otro diagnóstico, confirmándose con la intervención quirúrgica y posteriormente anatomía patológica.

Palabras clave: Quiste de uraco, abdomen agudo, apendicitis. (Fuente: DeCS BIREME).

\begin{abstract}
Case report: The literature states that the urachus cyst is rare, so the diagnosis is even more difficult to establish, because symptoms only manifest when a complication already exists, so it can be assumed that many people have a urachus cyst, and without having symptoms, they continue with their life activities without problems. Next, we present the case of a patient, who admitted to a clinic suggestive of an acute abdomen due to appendicitis, but the imaging tests revealed another diagnosis, confirming with the surgical intervention and subsequently pathological anatomy.
\end{abstract}

Keywords: urachus cyst, acute abdomen, appendicitis. (source: MeSH NLM).

\footnotetext{
Correspondencia:

Leo Tomayquispe De la cruz Número de celular: (+511) : 998417921 Correo Electrónico: leo_td_243@hotmail.com

Contribuciones de autoría:

LTQ y MFP contribuyeron por igual en la concepción, redacción, revisión y aprobación final del manuscrito.

Como citar:

Tomayquispe-De la Cruz L. Flores Paredes M. Quiste de uraco complicado. Diagnóstico diferencial de abdomen agudo. Reporte de un caso. Rev méd panacea. 2020; 9(1): 57-6o. doi: https://doi.org/10.35563/rmp.v9i1.298
} 


\section{INTRODUCCIÓN}

El alantoides es una membrana que deriva del tubo digestivo primitivo, la cual en una porción va comunicar la vejiga con el ombligo, dicha estructura recibe el nombre de uraco. Este uraco sirve para que el feto orine durante las primeras semanas de vida, y esta se debe cerrar aproximadamente en la $12^{\circ}$ semana de gestación (1).

Este conducto se debe cerrar completamente en el último mes de gestación, para así formar el ligamento umbilical medio del adulto (2). Los remanentes uracales se forman cuando este no se cierra completamente (3). Este remanente pasa desapercibido hasta que se complica, y por las similitudes en la sintomatología que presentas con otras enfermedades más comunes, como apendicitis o problemas urinarios.

\section{PRESENTACION DEL CASO}

Paciente femenina de 32 años de edad, cesareada anterior 3 veces y 1 episodio de litiasis renal hace 5 años, antes de su hospitalización acude 2 días seguidos a emergencia , y es dada de alta con analgésicos, al tercer día que acude a emergencia manifiesta dolor tipo cólico en hemiabdomen inferior derecho asociado a molestias urinarias y alza térmica ; el examen físico revela taquicardia $\left(\mathrm{FC}=120^{\prime} \mathrm{X}\right)$ y fiebre $\left(T=38.4^{\circ}\right)$, además dolor a la palpación en fosa iliaca e hipocondrio derecho, por lo cual es catalogado como un Síndrome doloroso abdominal y una posible infección urinaria, posteriormente los exámenes de laboratorio de admisión revelan leucocitosis $15.28 \times 103$ cells/uL, anemia con $\mathrm{Hb}$ $10.8 \mathrm{~g} / \mathrm{dL}$ y el uroanálisis mostraba hematuria +50 hematies $\mathrm{x} / \mathrm{c}$, por lo cual se crea una duda entre apendicitis aguda y litiasis renal, frente a esto se solicita una ecografía transvaginal que muestra una imagen quística a nivel de fondo de vejiga (fig. 1 ),

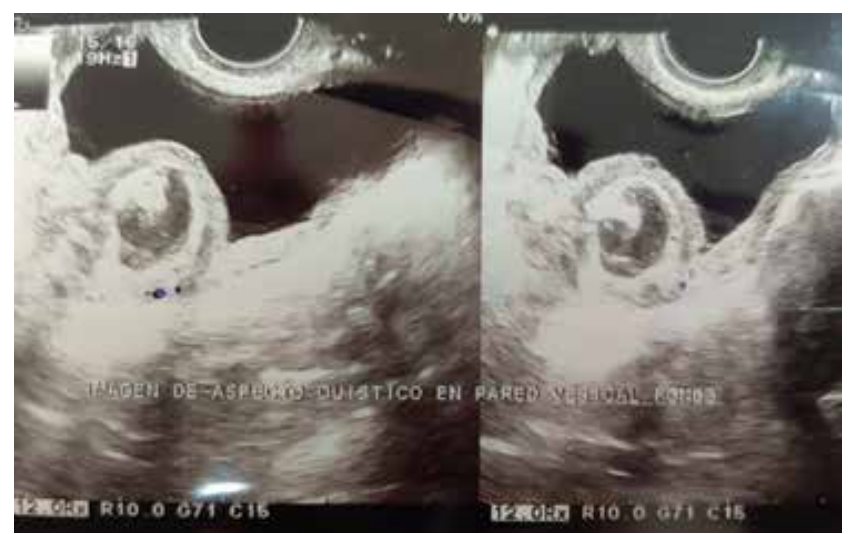

Figura 1. Ecografía Transvaginal que muestra imagen quística en fondo de vejiga.

sugerente de quiste de uraco complicado, para poder mejorar la valoración del caso se solicitó TAC pélvica $\mathrm{c} / \mathrm{c}$ que concluyo en colección en región pre-vesical (fig. .2). Con el diagnostico ya establecido la paciente recibió tratamiento antibiótico y fue preparado para resección quirúrgica. La pieza extirpada fue llevada a anatomía patológica que dio como resultado tejido fibroconectivo, fibroblastos, fibras colágenas, sin atipia. La paciente fue dada de alta a los 2 días con evolución favorable, en la cita control a los 7 días, manifestó que el dolor y malestar urinario ya cedieron.

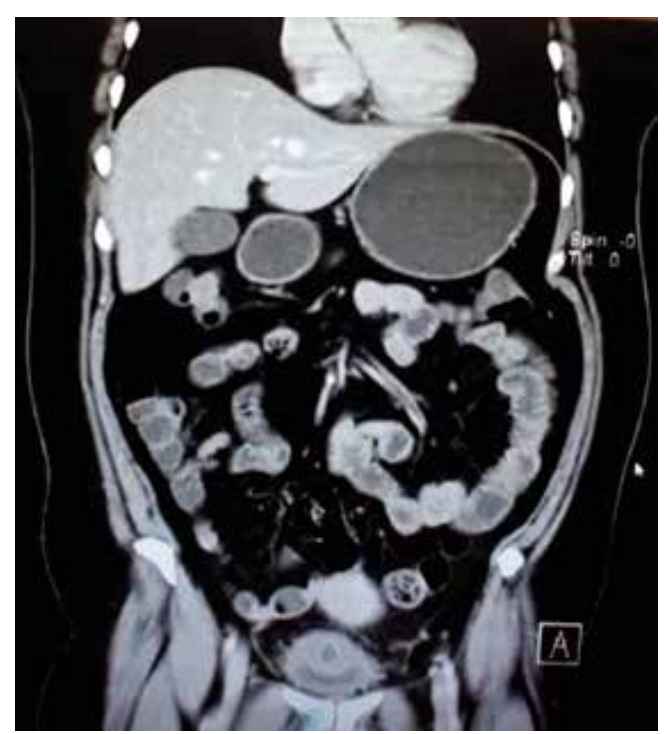

Figura 2. TAC Axial que muestra colección adyacente a la pared anterior de vejiga

\section{DISCUSIÓN}

El uraco es un tejido remanente el cual se extiende desde la vejiga hasta el ombligo, este se debe cerrar completamente, un cierre incompleto de este remanente da lugar a anomalías (4), las cuales pueden ser de 4 tipos uraco persistente, quiste de uraco, seno uracal y divertículo uracal. El quiste de uraco es el segundo tipo de anomalía más frecuente, seguido del uraco persistente $(1,5)$.

Cuando dicha estructura persiste, la mayoría de veces pasa de manera asintomática, lo cual hace difícil el diagnostico, y solo da clínica cuando ya existe una complicación de por medio, frecuentemente una infección, está a la vez manifestar patologías aguadas del abdomen y/o pelvis (6).

Debido a la presentación clínica variada que presenta como es el dolor, fiebre, náuseas, vómitos , sin olvidar que en muchas ocasiones presenta síntomas urinarios que pueden simular una cistitis o pielonefritis ,y además de su baja frecuencia , es habitual fallar en el diagnóstico , por lo que a todo paciente antes de un tratamiento quirúrgico por la sospecha de abdomen agudo, se debe realizar un ultrasonido y de acuerdo a los hallazgos complementar con otros exámenes auxiliares $(7,8)$.

Una vez establecido el diagnostico con ayuda del US o TAC, la conducta inicial debe ser con antibióticos y el manejo definitivo, quirúrgico a fin de evitar complicaciones como infecciones, rupturas a fin de 
conseguir una mejor evolución $(2,9,10,11)$. Del mismo toda la pieza quirúrgica debe ir a anatomía patológica, debido a su alto potencial de transformación neoplásica (3).

A pesar de que la mayoría de quistes de uraco observan con mayor frecuencia en la niñez (12), el presente caso esta referido a una paciente adulta femenina con un quiste de uraco complicado en la vejiga.

\section{CONCLUSIONES}

Reportamos el primer caso documentado de Quiste de Uraco complicado en la Región Ica , a pesar de ser una patología rara, debe ser considerado como un diagnostico diferencial frente a un paciente que acude por fiebre acompañado de dolor en hipocondrio y fosa iliaca derecha, por lo cual se debe realizar a todo paciente por lo menos un examen de ultrasonido para poder corroborar el diagnostico, teniendo en cuenta que la clínica que presenta esta patología es muy parecida a una apendicitis aguda y/o litiasis renal, entre otras.

- Consentimiento del paciente: La paciente autoriza plenamente la publicación de su caso.

- Agradecimientos: Damos las gracias a los Radiólogos del Hospital San José de Chincha, Perú, por apoyar al desarrollo de este reporte de caso. 


\section{REFERENCIAS BIBLIOGRÁFICAS}

1. Elumalai G . "CONGENITAL ANOMALIES OF URACHUS" EMBRYOLOGICAL BASIS AND ITS CLINICAL SIGNIFICANCE. Elixir Embryology 103 (2017) 45676-46679

2. Garcia A , Ponce F, Farfan F . Quiste uracal. Presentación de un caso y revisión de la literatura. Rev Mex Urol 2005; 65(6) : 459-462

3. Lucerna A, Lee J , Espinoza J , Herts R, Scali V . An Adult with a Remnant Urachus Anomaly Diagnosed in the Emergency Department. Hindawi [Internet]. Case Reports in Emergency Medicine, Vol 2018, Article ID 6051871, 3 pages, 2018.

Disponible en

https://www.hindawi.com/journals/criem/2018/605187 $1 /$

4. Cherese R. Severson APRN, MSN, FNP-BC . Enhancing nurse practitioner understanding of urachal anomalies . J Am Acad Nurse Pract. 2011 Jan;23(1):2-7.

5. Zamora G. Elizabeth, O'Brien S Andrés. URACO: ANOMALIAS DEL DESARROLLO, CARACTERISTICAS ANATOMICAS Y PRESENTACION DE DOS CASOS. ReV. chil. radiol. [Internet]. 2006 [citado 2019 Oct 30] ; 12( 1 ): 9-11.

Disponible en:

https://scielo.conicyt.cl/scielo.php?script=sci_arttext $\&$ pid=S0717-93082006000100004\&lng=es.

6. Gimeno Argente V., Domínguez Hinarejos C., Serrano Durbá A., Estornell Moragues F., Martínez Verduch M., García Ibarra F.. Quiste de uraco infectado en edad infantil. Actas Urol Esp [Internet]. 2006 Dic [citado
2019 Oct 30] ; 30( 10$):$ 1034-1037.

Disponible en:

http://scielo.isciii.es/scielo.php?script=sci_arttext\&pi $\mathrm{d}=$ S0210-48062006001000011\&lng=es.

7. Mayor MC , Davila-Serapio F, Rivera-Cruz JM , Rosiles-Dominguez C . Error en el diagnóstico de un quiste de Uraco. Reporte de un caso . Rev Sanid Milit Mex 2009; 63(5): 255-257

8. Kaya S, Haluk Bacanakgıl B, Soyman Z, Kerımova R , Havare B, Kaya B, "An Infected Urachal Cyst in an Adult Woman," Case Reports in Obstetrics and Gynecology, vol. 2015, Article ID 791408, 2 pages, 2015.

Disponible en :

https://www.hindawi.com/journals/criog/2015/79140 8/

9. Hwan Lee $S$, Im Lee H, Gue Shin D. Urachal cyst presenting with huge abscess formation in Adults. J Korean Surg Soc 2012 Oct ;83(4):254-257

10. Sup Kim J, Sik Youn C, Woo Yang S, Ho Kim W, Hwang E, Sumg Lim J . Infected Urachal Cyst . Korean J UTII 2009:4(2):232-234

11. Elkbuli A, Kinslow K, Ehrhardt JD Jr, Hai S, McKenney M, Boneva D. Surgical management for an infected urachal cyst in an adult: Case report and literature review. Int J Surg Case Rep. 2019;57:130-133.

12. Yildirim H, Koç M , Poyraz K. Urachal Cyst: US, CT, and MRI Findings (Case Report). F.Ü. Sağ. Bil. Derg. 2007: 21 (3): $145-148$

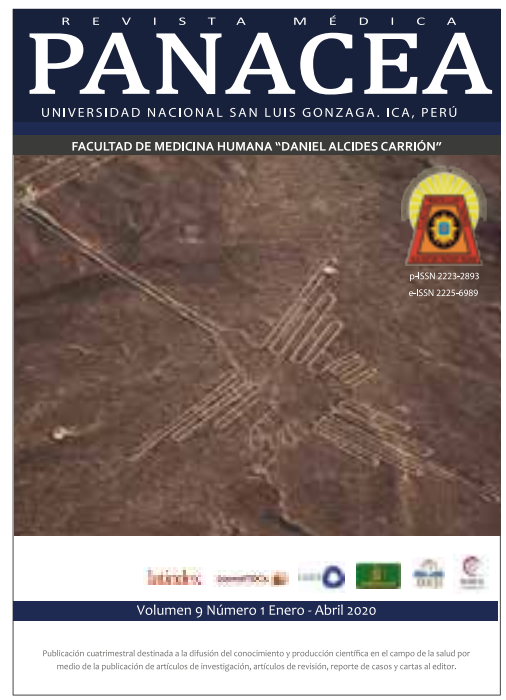

